\title{
Desenvolvimento de um método de avaliação monetária de árvores urbanas e aplicação à situação de Maringá - PR*
}

\author{
Valmir Augusto DetZel** \\ Miguel Serediuk Milano**** \\ Vitor Afonso HoEflich $* * * *$ \\ CARLOS FIRKOWSKI******
}

\begin{abstract}
RESUMO
O presente trabalho objetivou estabelecer um método de avaliação monetária de árvores individuais, componentes da arborização urbana, baseado nos custos de manutenção das árvores de rua de Maringá. Com cerca de 240.000 habitantes (1991), Maringá possuía em 1988 aproximadamente 62.818 árvores de rua, responsáveis por 13,6 $\mathrm{m}^{2}$ de área verde por habitante. O município apresenta legislação de proteção a arborização (Lei 2.585/89) que determina, aos causadores dos danos em árvores, o pagamento de indenização e multa com valores calculados em função da circunferência do tronco (CAP) que se revelam de difícil aplicação. Assim, com o apoio da Prefeitura Municipal de Maringá (PMM), foi elaborado um sistema de avaliação monetária de árvores urbanas que desse respaldo técnico-econômicas às penalizações e que levasse em conta as operações de implantação e manutenção da arborização. Os dados coletados são referentes ao período de janeiro a junho de 1992. A elaboração do método exigiu a determinação dos custos médios de mudas, tendo por base os preços médios de aquisição praticados pelas empresas privadas da região. As despesas realizadas pela administração municipal influentes no custo da arborização, tais como, manutenção de pessoal, aquisição de material de consumo e insumos, de bens duráveis e despesas administrativas, foram obtidas através da análise dos balancetes mensais da PMM para o período considerado. Foram computadas, ainda, as despesas geradas pela realização da poda pela Companhia Paranaense de Energia. O método, ora proposto, determina o valor da árvore através da aplicação do custo da muda, por espécie e da idade de plantio em uma equação de primeiro grau formada por componentes relativos a custos correntes, custos de bem capital e custos administrativos, corrigidos por um fator referente à taxa de juros na idade considerada ( $6 \%$ ao ano). O principal limitante a aplicação do método

* Artigo extraído em parte da tese de doutorado do 1 autor

** Eng. Florestal , MSc., Universidade Livre do Meio Ambiente

*** Eng. Florestal, MSc., Dr. Prof. Adjunto do Dpto de Silvicultura e Manejo, UFPR

***** Dr. Pesquisador da EMBRAPA/ CNPF

******ng. Florestal, MSc., PhD., Professor Adjunto do Depto de Silvicultura e Manejo, UFPR
\end{abstract}


é que se faz necessário conhecer a idade de plantio da árvore a ser avaliada. No caso de Maringá, a estratificação dos custos de mudas por espécie não se mostrou significativa, daí porque foram utilizados custos médios de mudas nas avaliações. Os valores das árvores entre 1 e 50 anos estabelecidos pelas fórmulas são equivalentes a respectivamente US\$ 60 e US\$ 6.850 .

Palavras-chave: arborização, avaliação monetária, árvores urbanas

\section{ABSTRACT}

Monetary and public-awareness evaluation of urban forestry: methodological application to the situation in Maringá - PR This work aimed to establish a method of monetary evaluation of individual trees, components of urban tree planting, based on the cost of maintenance of Maringá's street trees. With about 240,000 inhabitants (1991), Maringá possessed in 1988 approximately 62,818 urban trees, representing $13.6 \mathrm{~m}^{2}$ of green area per inhabitant. The municipality has a law protecting trees (Municipal Law 2,585/89), determining that those who cause damages to trees pay indemnity and fines in amounts calculated in relation to trunk circumference (CBH). Considering that the amounts stipulated by law are very high it is consequently difficult to enforce. Maringá Town Hall (PMM) decided to support the preparation of a system monetary evaluation of urban trees that would provide technical-economic backing to penalties, taking into account the planting and maintenance of trees. The data collected for the development of the monetary evaluation method encompass the period from January to July, 1992. The design of method demanded the setting of the average costs of seedlings, based on average purchasing prices practiced by the private trade in the region. The expenses incurred by Town Hall influencing tree-planting costs, such as staff maintenance, acquisition of consumables and fertilizers, durable goods and overheads, were obtained by the analysis of the monthly balance sheets of the period in question. Moreover, the expenses generated by the pruning made by the Paraná Power Company (COPEL) were also taken into account. The method now processed determines the value of a tree by applying the cost of seedling, per species, and plant age to a linear equation formed by the components concerning current costs, capital goods costs and overheads, corrected by a factor related to the interest rate at the considered age $(6 \%$ a year). The main limitation to the application of the method is that it is necessary to know de age of the tree under evaluation. In the case of Maringá, the stratification of the costs of seedlings per species did not show significance; therefore average costs of seedlings were employed in evaluations. The values of trees between 1 and 50 years of age, set by the formula, are equivalent to respectively US\$ 60 and US\$ 6,850 .

Key words: arborization, monetary evaluation, tree value, urban trees

\section{INTRODUÇÃO}

$\mathrm{O}$ volume de recursos aplicados pelas administrações municipais para o estabelecimento de arborização em ruas, praças e parques, quase sempre traduz a importância deste componente da infra-estrutura urbana para os cidadãos. 
Por sua vez a avaliação monetária das árvores públicas não objetiva o conhecimento de seu preço de mercado ou de seus sub-produtos para posterior venda. Valores monetários inerentes às árvores urbanas, especialmente aquelas situadas nas ruas, têm aplicação direta no planejamento das atividades relativas a implantação e manutenção da arborização e na otimização dos recursos a ela destinados. A determinação de valores monetários para árvores individuais, justifica-se também pela necessidade de aplicação de multas, indenizações e isenções estabelecidas segundo critérios de valoração de comprovadas eficácia e veracidade.

Neste contexto, o objetivo do presente trabalho é apresentar um método de avaliação monetária de árvores individuais componentes da arborização urbana, baseado nos custos de implantação e manutenção de árvores de rua da cidade de Maringá - PR.

\section{REVISÃO DE LITERATURA}

\section{BENEFÍCIOS DA ARBORIZAÇÃO URBANA}

A vegetação urbana, representada tanto pelas áreas verdes como pela arborização de ruas é responsável por uma ampla gama de benefícios ambientais e sócio-econômicos variáveis em qualidade e intensidade. Genericamente, os benefícios decorrentes da arborização são variáveis, também, ao longo do tempo e de acordo com as alterações do espaço urbano e com as necessidades e hábitos dos cidadãos (DWYER et al., 1992).

A importância da arborização pode traduzir-se pelas comprovadas ações de melhoria microclimática, de controle das poluições sonora, visual e atmosférica e pela melhoria estética das cidades. As amplas possibilidades de uso funcional das árvores, relacionadas à arquitetura e engenharia, permitem a obtenção de benefícios sociais e econômicos que contribuem para a melhoria da qualidade de vida das pessoas. Árvores e áreas verdes proporcionam estímulos à sensibilidade humana, colaboram para a saúde física e mental do homem; e fornecem, ainda, abrigo e alimentação para a fauna urbana (SMITH \& DOCHINGER, 1976; GREY \& DENEKE, 1978; BERNATZKI, 1980; BARTEINSTEIN, 1981; MILANO, 1984 e 1988; TAKAHASHI \& MARTINS, 1987).

DWYER et al., (1992) citam, ainda, que "o entendimento da ampla gama de benefícios associados à arborização das cidades, tanto quanto o conhecimento das corretas práticas de manejo são essenciais para a melhoria do ambiente urbano. Os benefícios a considerar incluem os bens e serviços produzidos pelas árvores e áreas verdes urbanas, sendo que enquanto alguns deles são facilmente expressos em moeda ou números, outros são de difícil quantificação". Áreas verdes urbanas, quando estabelecidas de forma adequada, geram empregos diretos e indiretos e propiciam a geração de divisas pelo considerável aumento do consumo de bens e serviços (JIM, 1987; DETZEL, 1992; DWYER et al., 1992). 


\section{AVALIAÇÃO DE ÁRVORES URBANAS}

As tentativas de estabelecimento de valores às árvores urbanas nos Estados Unidos remontam ao fim século passado, devido à necessidade de cobrança de indenizações por danos causados às árvores. A maioria das variáveis utilizadas na determinação do valor das árvores relaciona-se com sua idade, espécie, condição fitossanitária e localização. Apesar de sua importância e dependendo do objetivo do método considerado, algumas variáveis são de difícil utilização na avaliação de árvores, seja pelo caráter subjetivo que apresentam ou pelo fato de só possibilitarem a determinação do valor da madeira ou da biomassa resultante de operações de poda ou remoção da arborização. Alguns aspectos relacionados aos valores representados ou associados a árvores urbanas são apresentados em seguida.

Valores alternativos: - conforme definido por KIELBASO (1971), esses valores dizem respeito às possibilidades alternativas de investimento (ouro, mercado de capitais, mercado imobiliário, poupança ou outro tipo de aplicação) do capital empregado para o estabelecimento e manutenção da arborização de determinado lugar, sendo que na prática este tipo de associação de valores dificilmente é utilizada em avaliações monetárias de árvores urbanas, isoladas ou em conjunto.

Árvores como bens de capital urbano: - ao considerar uma árvore como qualquer outro elemento da infra-estrutura urbana, sob um enfoque não emocional, a exemplo de postes para transmissão de energia, escolas e hospitais públicos, entre outros, pode-se valorizá-la em importância e em dinheiro de forma proporcional e equivalente aos mesmos (KIELBASO, 1971; GREY \& DENEKE, 1978).

Valores de biomassa ou subprodutos: - os diferentes produtos possíveis de serem obtidos a partir de árvores, como madeira serrada, lâminas, lenha, carvão, entre outros, podem ser indicativos do valor das árvores. Vários autores consideram a importância e os valores gerados pelo aproveitamento de biomassa relacionado às possibilidades de uso dos resíduos provenientes de árvores urbanas para os mais variados fins, como parâmetros de avaliação monetária para árvores urbanas (KIELBASO, 1971; DeVOTO, 1979; LEMPICKI, 1979; LOWERY, 1979; MILLS, 1979; PARDO, 1979; WALKER, 1979; WHITMER, 1979).

Valores de propriedade: - GREY \& DENEKE (1978), citam que a valorização de propriedades pela existência de arborização está relacionada ao nível sócio-econômico e cultural das pessoas; MORALES (1980), após avaliar propriedades residenciais e comerciais, concluiu que as árvores contribuem significativamente para o aumento do valor de venda dos imóveis, representando cerca de 6 a $9 \%$ de seu preço final, enquanto DWYER et al. (1992), consideram que as árvores, por contribuírem com o aumento do valor de propriedades, produzem efeito direto nos ganhos econômicos por parte do município através do aumento do valor de taxas e impostos territoriais urbanos, podendo desta forma ser encaradas como investimento com retorno real anual. 
Valores monetários da arborização e legislação: - árvores em cidades muitas vezes estão relacionadas a questões de multas, indenizações, deduções e/ou isenções de impostos e taxas, resultantes de ações punitivas ou compensatórias. Diversos autores discorrem sobre a legislação a ser aplicada tanto ao município por ter causado danos a árvores, quanto ao responsável pelo manejo da arborização, por ter negligenciado o seu manejo tendo como conseqüência prejuízos a particulares. Os deveres da administração pública também são citados por AKROYD (1986), que detalha situações de danos provocados por árvores em bens particulares, justificando a existência de legislação específica que proteja os direitos de indenização/compensação do cidadão prejudicado, por parte da administração municipal. Muitas cidades possuem leis que estabelecem multas por danos ou morte provocados a árvores, com valores variáveis dependendo da espécie afetada e de seu porte (FARHAT, 1990; PMM, 1991), no entanto, os valores previstos, em geral foram estabelecidos empiricamente.

Valores de manutenção: - estes valores são amplamente utilizados como parâmetros para avaliação de árvores urbanas, sendo que os custos relacionados ao controle de doenças, às podas de limpeza e formação e aos reparos de calçadas e guias são os mais freqüentes (MILLER \& SILVESTER, 1981; SHERWOOD \& BETTERS, 1981; JOHNSTONE, 1983; KOSTICHA \& CANNON, 1984; DREISTADT \& DAHLSTEIN, 1986; LOHMANN, 1988). JIM (1987) cita a importância da determinação do valor da árvore como base para o planejamento anual da remoção, manutenção e implantação da arborização; para o estabelecimento de valores de multas, indenizações e punições; e, para a própria conscientização sobre o patrimônio físico-financeiro instalado nas cidades. Alguns autores (BRYANT, 1983; NOSSE, 1983; DREISTADT, 1986) destacam a necessidade de considerar componentes indiretos à manutenção da arborização nos processos de avaliação, tais como perdas diversas por desligamento de energia durante as atividades de poda e perda temporária do valor estético da árvore imediatamente após alguns tipos de operações de manutenção. Ainda, JOHNSTONE (1983) identifica problemas nos sistemas de distribuição elétrica causados por árvores de rua e sugere práticas de manejo que além de solucionar tais problemas também diminuam gastos com a manutenção de árvores, deixando claro o componente custo de manutenção como justificativa para a adoção de práticas de planejamento para o manejo da arborização.

\section{MÉTODOS DE AVALIAÇÃO MONETÁRIA DA ARBORIZAÇÃO}

Inexistentes no Brasil até o momento, os métodos de avaliação monetária de árvores urbanas estão bastante desenvolvidos nos Estados Unidos e em alguns países da Europa. Para a realização deste trabalho foram analisados alguns métodos utilizados nos Estados Unidos, entre os quais O Guia de Avaliação de Michigan (MSUFD \& MFPA, 1975 e 1986) e o Guia de Avaliação da Sociedade Internacional de Arborização Urbana (ISA, 1988), o primeiro de âmbito regional e o outro, nacional. 
O Guia de Avaliação de Michigan prevê duas formas de avaliação de árvores individuais. A primeira, denominada método da substituição ou reposição, deve ser utilizada em avaliações de árvores com diâmetro menor que 6 polegadas (aproximadamente $16 \mathrm{~cm}$ ) e baseia-se nos custos gerados pelas operações de substituição e transplante de uma árvore por outra de tamanho equivalente. A segunda, é denominada fórmula de avaliação e tem utilização prevista para árvores com diâmetro entre 7 e 40 polegadas (aprox. 16 a $102 \mathrm{~cm}$ ) e considera: valores percentuais relativos à espécie (apresenta tabela auxiliar com 110 espécies); a condição fitossanitária utilizando 6 parâmetros (condição do tronco, taxa de crescimento recente, arquitetura da árvore, existência de doenças e ataques de insetos, características da copa e expectativa de vida remanescente); e, por fim, um fator referente à localização da árvore e seu enquadramento no contexto urbano. O valor final é resultante da aplicação dos percentuais obtidos pela análise dos itens acima descritos sobre o resultado do produto entre a área transversal do tronco em polegadas quadradas e o valor básico de US\$ 21 por polegada quadrada.

O Guia de Avaliação da Sociedade Internacional de Arborização também estabelece dois meios de avaliação de árvores individuais, apresentando considerações sobre os procedimentos preliminares, relacionados à diagnose dos problemas eventualmente apresentados pelas árvores. Os fatores considerados, independentemente do meio utilizado são: tamanho - baseado na área transversal do tronco à altura do peito $(1,35 \mathrm{~m})$; espécie - dependente dos atributos da árvore; condição - que engloba o estado fitossanitário, estrutural e de arquitetura, entre outros; e a localização - referente à avaliação paisagística da árvore com o meio. O primeiro meio de avaliação, denominado método da relocação/reposição baseia-se nos custos de substituição de árvores menores que 8 polegadas de diâmetro de tronco (aprox. $20 \mathrm{~cm}$ ) e inclui avaliações da espécie, tamanho da árvore e localização, aplicados sobre um valor básico expresso em dólar. Constam exemplos de árvores situadas entre 5 e $20 \mathrm{~cm}$ de DAP, cujos valores atingem entre US\$ 250 e US\$ 1.900 , respectivamente. O método da fórmula básica aplica-se a árvores com diâmetro entre 9 e 40 polegadas (aprox. 22 a $101 \mathrm{~cm}$ ), sendo que o valor básico por polegada quadrada de área transversal do tronco é de US\$27, sobre o qual são aplicados os fatores espécie, condição e localização, expressos em percentuais com caráter detrator.

\section{MATERIAL E MÉTODOS}

\section{CARACTERIZAÇÃO DA ÁREA DE ESTUDOS}

Construída a partir de 1944 de acordo com um projeto urbanístico detalhado, Maringá apresenta vias de trânsito amplas e arborizadas, estabelecidas sobre relevo suave-ondulado e em terras de alta fertilidade. A despeito de que tenha sido projetada, originalmente, para uma população de 50.000 habitantes, o município de Maringá contava em 1980 com 
aproximadamente 164.000 habitantes (IBGE, 1982), dos quais cerca de 157.500 eram residentes urbanos. A população oficial segundo o censo de 1991, é de 239.930 habitantes, tendo ocorrido, portanto, um incremento de $46 \%$ na última década (IBGE, 1991).

O sistema viário da cidade encontra-se totalmente planejado (incluindo as áreas para ocupação futura) e conta com aproximadamente $1.607 \mathrm{~km}$ de ruas e avenidas abertas ao tráfego, dos quais cerca de $46 \%$ já pavimentados (PMM, 1988).

Em 1988 a cidade dispunha de 84 áreas verdes publicas (80 praças e 4 parques) e uma área verde privada com acesso público permitido, conforme MILANO (1988). A maior unidade verde apresenta área de 59 ha e a menor $210 \mathrm{~m}^{2}$, sendo que a distribuição espacial das unidades é bastante homogênea. Além destas áreas, a legislação municipal protege ainda os 753 ha de fundos de vales, dos quais cerca de $28 \%$ encontram-se na malha urbana atualmente ocupada, pela obrigatoriedade da preservação marginal e pela imposição de restrições de uso (MILANO, 1988).

Segundo MILANO (1988), as ruas contam com 62.818 árvores de 76 espécies, sendo que $95 \%$ da população arbórea total é representada por apenas 15 espécies. A qualidade individual das árvores é boa ou satisfatória em $85 \%$ da população e os danos físicos que se apresentam são resultantes principalmente de operações de poda mal executadas (29\%), vandalismo ou acidentes $(25 \%)$ e problemas fitossanitários $(7 \%)$.

A relação área verde por habitante, considerados dados de 1988 e relativa apenas às praças e parques é de $6,7 \mathrm{~m}^{2} / \mathrm{hab}$. Considerando-se também a arborização de ruas $\left(14 \mathrm{~m}^{2} / \mathrm{hab}\right.$.), esta razão passa para $21 \mathrm{~m}^{2} / \mathrm{hab}$., com grandes possibilidades de incremento (MILANO, 1988).

Desde junho de 1973, Maringá estabeleceu, através da Lei 995/73, a proteção das árvores públicas. Essa legislação, posteriormente alterada pela Lei 2.585/89, estabeleceu multas e indenizações, com valores definidos empiricamente, a serem aplicadas aos causadores de danos ou morte à arborização da cidade. A Tabela 1 apresenta os valores de multas atualmente em vigor, expressos em Unidades Fiscais Municipais (UFM) de Maringá, valores estes que, segundo FARHAT (1990), por serem elevados, são de difícil aplicação. 
Tabela 1 - Valores de multas previstos na legislação municipal de Maringá (Lei 2.585/89)

Table 1 - Citation values in the Maringá county legislation (Law 2.585/89)

\begin{tabular}{|c|c|c|c|c|c|c|c|c|c|c|}
\hline \multicolumn{11}{|c|}{ Multas em UFM/fines in UFM } \\
\hline \multicolumn{6}{|c|}{ Danos/Damage } & \multicolumn{5}{|c|}{ Morte/Death } \\
\hline Espécie/Cap & até 30 & $31 / 60$ & $61 / 90$ & $91 / 130$ & $>131$ & até 30 & $31 / 60$ & $61 / 90$ & $91 / 130$ & $>131$ \\
\hline $\begin{array}{l}\text { figueira } \\
\text { palmeira } \\
\text { tamareira }\end{array}$ & 50 & 60 & 70 & 80 & 100 & 100 & 200 & 400 & 800 & 1000 \\
\hline $\begin{array}{l}\text { alecrim } \\
\text { canelinha } \\
\text { flamboyant } \\
\text { ipê-amarelo } \\
\text { ipê-roxo } \\
\text { pau-ferro } \\
\text { quaresmeira } \\
\text { tipuana }\end{array}$ & 40 & 50 & 60 & 70 & 80 & 80 & 180 & 350 & 500 & 700 \\
\hline $\begin{array}{l}\text { bauhínia } \\
\text { espatódea } \\
\text { jacaranda } \\
\text { ligustrum } \\
\text { magnólia } \\
\text { sibipiruna } \\
\text { outras }\end{array}$ & 30 & 35 & 40 & 50 & 60 & 60 & 150 & 250 & 400 & 500 \\
\hline
\end{tabular}

Avaliação monetária da arborização urbana

Partindo-se do pressuposto de que é necessário determinar o valor monetário de árvores individuais para fins de planejamento e para compensação de perdas do capital investido pela municipalidade com árvores públicas vitimadas por danos, assumiu-se que o valor da árvore é equivalente aos custos de implantação e manutenção da mesma no decorrer do tempo, corrigido monetária e financeiramente.

Tendo em vista a dificuldade de obtenção dos custos gerados pelo tratamento individual de árvores de rua de Maringá e a possibilidade de determinação do número de pessoas envolvidas com a arborização da cidade, optou-se pela utilização dos custos totais de manutenção para a população arbórea considerada como base de determinação dos custos médios por intervalo de tempo.

Os dados coletados para o desenvolvimento do método de avaliação monetária de árvores urbanas são referentes ao período de janeiro a junho de 1992. Assumiu-se que os dados coletados são representativos para o período e, portanto, servem de base para extrapolações para um ano todo (1992).

A unidade ou índice monetário utilizado no cálculo de custos foi a UFM de Maringá para fins de impostos municipais, equivalente em novembro de 1992 a US\$23,81 pelo câmbio comercial médio do mês.

Todos os preços relativos à compra de equipamentos, mudas e prestação de serviços foram considerados como custos para a elaboração do método. A taxa efetiva de juros considerada no cálculo de custos foi de $0,5 \%$ ao mês. A aplicação desta taxa é decorrente da necessidade de se computar rendimentos monetários mínimos possíveis de se obter através da aplicação de 
dinheiro no mercado financeiro ou em outras atividades competitivas (KIELBASO, 1971).

\section{COMPONENTES DE CUSTO DE IMPLANTAÇÃO E MANUTENÇÃO DA ARBORIZAÇÃO}

Apesar de normalmente serem consideradas para um grupo de árvores, as despesas de manutenção podem ser utilizadas como determinantes do valor individual de árvores à medida que se estabelece a razão entre o total das despesas para o tratamento de um número " $n$ " de árvores no decorrer de um determinado tempo, considerando-se também a taxa de atratividade.

Para o desenvolvimento do método de avaliação foi necessário o levantamento dos seguintes custos:

a) formação/aquisição da muda a ser plantada ou preço médio de venda da muda no mercado regional;

b) mão-de-obra e custos de materiais de consumo utilizados direta ou indiretamente, no processo de implantação/manutenção;

c) custos de bens de capital (equipamentos, veículos, máquinas e tratores);

d) custo de administração dos recursos humanos e materiais.

\section{CUSTO DE MUDAS}

Para efeito de cálculo no processo de avaliação da arborização, partiuse do princípio que a Prefeitura Municipal de Maringá (PMM) faria a compra das mudas destinadas à arborização de ruas a preços de mercado na região (ou que o custo de produção de mudas no viveiro municipal seria igual ao preço de venda das mudas nos viveiro privados).

O cálculo do componente custo de mudas no método de avaliação, considerou o valor médio da muda praticado por 3 viveiros visitados, por espécie, sobre o qual é aplicada a taxa de juros no decorrer do tempo (idade da árvore). Em Maringá o custo de muda considerado nos cálculos representa a média de todos os preços encontrados nos viveiros para as diversas espécies, porque as variações verificadas não são significativas a ponto de determinar valores diferenciados por espécie para árvores de mesma idade.

\section{DESPESAS CORRENTES}

O custo das operações de implantação e manutenção, denominados despesas correntes, são relativos a mão-de-obra, material de consumo (escritório e campo) e demais insumos necessários para o estabelecimento da arborização da cidade. Para a formulação do método optou-se pela utilização dos valores de despesas correntes relacionados nos balancetes mensais dos departamentos/seções envolvidas com a arborização na PMM.

Obteve-se, também, o número de funcionários envolvidos com arborização de ruas, através de informações coletadas junto ao departamento responsável pelos recursos humanos da administração local. Foram coletados, igualmente, os custos de operações de poda executadas pela Companhia 
Paranaense de Energia (COPEL), através de empreiteiras, nas árvores situadas sob fiação elétrica de baixa e alta tensão.

O valor do componente despesas correntes foi obtido em função da somatória dos montantes aplicados pela PMM e pela COPEL, do número de funcionários da PMM envolvidos com arborização e do número total de árvores tratadas no período considerado. $\mathrm{O}$ valores desse componente no decorrer do tempo foram calculados considerando-se a aplicação da taxa mínima de atratividade nominal de $6 \%$ ao ano.

\section{DESPESAS COM BENS DE CAPITAL}

Considerando que os bens duráveis existentes na PMM não suprem as necessidades de atendimento na manutenção das árvores e que, em alguns casos, estão completamente depreciados, para efeito de cálculo, optou-se pela substituição teórica dos veículos e equipamentos que seriam necessários ao bom andamento dos trabalhos. Foram considerados os tipos e capacidades dos equipamentos existentes e as necessidades de adequação dos mesmos em função do volume de trabalho existente. Uma vez definidos os equipamentos, foram considerados os seus custos de aquisição e manutenção, tomando-se por base os parâmetros e indicativos fornecidos pelos próprios fabricantes.

$\mathrm{O}$ valor do componente despesas com bens de capital, foi calculado em função do custo total de aquisição e manutenção destes equipamentos (despesas fixas e variáveis), do número de árvores atendidas no período considerado e da aplicação da taxa de atratividade para o período.

\section{DESPESAS ADMINISTRATIVAS}

Os custos referentes a gestão dos recursos humanos, materiais e financeiros envolvidos em todas as operações de implantação e manutenção da arborização, foram obtidos através de cálculos utilizando os valores despendidos no período de janeiro a junho de 1992, constantes nos balancetes mensais da Diretoria de Administração da PMM.

O valor do componente administrativo no método de avaliação foi calculado em função dos totais monetários despendidos pela diretoria, do número total de funcionários da administração municipal da PMM, do número de funcionários envolvidos com arborização e do número total de árvores atendidas no período de tempo considerado. Aqui também foram aplicadas taxas de atratividade em função do tempo.

\section{RESULTADOS E DISCUSSÃO}

\section{AVALIAÇÃO MONETÁRIA DA ARBORIZAÇÃO DE MARINGÁ \\ Cálculo do Número de Funcionários Envolvidos com Arborização de Ruas de Maringá}

Para determinação do método de avaliação monetária da arborização foi necessário o estabelecimento do número de funcionários diretamente 
envolvidos com a manutenção das árvores da cidade e, com base neste, o potencial de atendimento em número de árvores pela equipe de manutenção.

A Seção de Parques e Jardins, componente da Divisão de Proteção ao Meio Ambiente - DPMA (125 funcionários) da Diretoria de Serviços Públicos é responsável pela implantação e manutenção da arborização de ruas de Maringá, através do Departamento de Arborização e Áreas Verdes - DAAV. A divisão possui 3 gerentes que são responsáveis pelos 28 funcionários do DAAV e pelos 94 funcionários do Departamento de Parques e Bosques.

Considerando que os 3 gerentes tem atribuição de administrar os dois departamentos e que o objeto de interesse desse estudo é apenas o DAAV, o cálculo do número de funcionários envolvidos com arborização foi feito da seguinte maneira:

$\mathrm{n}^{\circ}$ func. env. $\mathrm{c} / \mathrm{arb} .=\mathrm{n}^{\circ}$ func. DAAV $+\left[\left(\mathrm{n}^{\mathrm{o}}\right.\right.$ gerentes $/ \mathrm{n}^{\circ}$ func. DPMA $)+\mathrm{n}^{\circ}$ func. DAAV $]$

Com a solução desta equação, obteve-se o número de 28.672 funcionários diretamente envolvidos com a arborização, sendo que, teoricamente, cada funcionário é responsável pela manutenção de 2.191 árvores.

\section{Cálculo do Potencial de Atendimento pela Equipe da PMM Expresso em Número de Árvores}

Partindo-se do número de árvores atendidas no período de 6 meses (12.562 árvores) e pressupondo-se que esta é a capacidade de atendimento máximo pela equipe em condições normais de trabalho, foi possível estabelecer o potencial de atendimento em árvores por mês (2.094 árvores/mês) e o intervalo de tempo teórico entre atendimentos em uma mesma árvore (30 meses) não importando o tipo de operação e considerando-se o total de árvores (62.818, segundo MILANO (1988)) existentes em Maringá.

\section{Cálculo do Custo de Mudas}

Uma vez verificado o preço médio de mudas (PM) aptas para implantação nas ruas da cidade, nos estabelecimentos de venda da região, o cálculo do componente custo de mudas (CM), em função da idade de plantio da árvore nas ruas (n), e considerando a taxa nominal de juros de $6 \%$ ao ano (efetiva de $0,5 \%$ ao mês - r), foi feito através da fórmula:

$\mathrm{CM}_{\mathrm{n}}=\mathrm{PM} \times\{1+[(\mathrm{n} \times \mathrm{r}) /(\mathrm{n} \times 12)]\}^{\mathrm{n} \times 12}$

$\mathrm{FC}=$ fator de correção necessário para a atualização financeira do valor da muda à taxa de juros considerada

Cálculo das Despesas Correntes Para a Manutenção da Arborização de Ruas 
É determinado pela somatória dos custos relativos a despesas correntes realizadas pela PMM e dos custos relativos à poda de árvores executada pela COPEL.

\section{A. Despesas da PMM}

Através dos balancetes mensais da PMM, obteve-se um valor monetário referente a despesas realizadas pela Diretoria de Serviços Públicos com a manutenção de árvores no período considerado de janeiro a junho de 1992. Desta maneira foi possível determinar um valor relativo ao funcionamento/manutenção dessa diretoria expresso em UFM que, teoricamente, representa o valor gasto com os insumos em 6 meses. Este valor, multiplicado pelo número de funcionários responsáveis pela arborização de ruas, dividido pelo número total de funcionários da diretoria e pelo número de árvores atendidas no período, equivale ao montante teórico médio despendido com a manutenção de uma árvore de rua $-\mathrm{V}_{\text {arb}}$. $\mathrm{O}$ resultado obtido foi igual a 1,801 UFM/árvore ou US\$ 42,88/árvore.

Os valores do componente custo de despesas correntes - CDC, em função da idade da árvore - $n$, corrigidos à taxa de juros de $6 \%$ ao ano (conforme fórmula do FC, demonstrada acima), foram determinados pela equação:

$\mathrm{CDC}_{\mathrm{n}}=\mathrm{V}_{\mathrm{arb}} \times \mathrm{FC}$

Na totalização dos custos, a cada 30 meses de idade da árvore foi acrescentado no cálculo uma vez o valor Varb, considerada a necessidade de se computar os custos relativos a despesas correntes efetuadas em função da execução de novas operações de manutenção em uma mesma árvore.

\section{B. Despesas COPEL}

A COPEL, responsável por todas as operações de poda de árvores situadas sob linhas de transmissão de energia elétrica, realizou no período de maio a novembro de 1991 , a poda de 30.838 árvores ao custo médio de 0,122 UFM/árvore ou US\$2,90/árvore - $\mathrm{CP}_{\text {fiação }}$.

Considerando que cerca de $51,7 \%$ das árvores de rua de Maringá situam-se sob fiação aérea (MILANO, 1988), ou seja, aproximadamente 32.477 árvores, as equipes empreitadas pela COPEL demoram no máximo 8 meses para podar todas as árvores nestas condições. Porém, conforme informações obtidas junto ao escritório regional da empresa, a poda em regime sistemático é realizada apenas uma vez ao ano. Desta maneira, é possível estabelecer o tempo de 12 meses como base de cálculo quanto ao intervalo de poda em uma mesma árvore.

Para facilitar a sistemática de cálculo, uma vez que não houve necessidade em se estabelecer fórmulas distintas para a avaliação de árvores sob a fiação, foi considerado 51,7\% do custo de poda da COPEL para todas as árvores que efetivamente sofre este tipo de poda. Desta maneira, mesmo que a 
árvore objeto de avaliação não esteja sob fiação elétrica, haverá em seu valor final uma fração relativa ao custo de poda como elemento compensatório.

Assim, o cálculo do componente custo de poda realizada pela COPEL $\left(\mathrm{CPC}_{\mathrm{COPEL}}\right)$, em função da idade da árvore, foi estabelecido pela somatória dos custos de poda por árvore, corrigidos pela taxa mínima de atratividade de 6\%, considerando-se o intervalo de um ano entre repetições da operação em uma mesma árvore. A cada ano de idade da árvore é acrescido uma vez o valor do custo unitário da poda no cálculo final da COPEL. Em síntese a fórmula de cálculo é:

$\mathrm{CPC}_{\mathrm{COPEL}}=0,517 \times \mathrm{CP}_{\text {fiação }} \times \mathrm{FC}$

Cálculo das Despesas com Bens de Capital para Manutenção da Arborização de Ruas de Maringá

Os veículos e equipamentos tiveram seus custos operacionais calculados com base em informações obtidas junto aos fabricantes, sendo que a participação mensal das despesas com bens de capital - $\mathrm{VARB}_{\text {cap }}$, considerados os custos fixos e variáveis, para a implantação/manutenção das árvores de ruas de Maringá foi de 0,16 UFM/árvore ou US\$ 3,81/árvore.

O componente de custo de bens de capital em função da idade da árvore $-\mathrm{CBC}_{\mathrm{n}}$, foi calculado de acordo com a fórmula:

$\mathrm{CBC}_{\mathrm{n}}=\mathrm{VARB}_{\text {cap }} \times \mathrm{FC}$

Da mesma maneira que nas despesas correntes, a taxa mínima de atratividade considerada foi de $6 \%$ ao ano e a cada 30 meses de idade da árvore foi acrescentado uma vez o valor do custo operacional variável dos equipamentos. Este acréscimo é referente a execução teórica de novas operações de manutenção em uma mesma árvore no decorrer do tempo. Os custos operacionais fixos não devem ser considerados porque foram calculados considerando taxas de recuperação de capital com valor igual a zero ao fim da vida útil do equipamento. Isto significa que, uma vez terminada a vida útil do equipamento, haveria sua reposição sem necessidade de novo investimento e, como consequiência, sem ônus ao contribuinte ou infrator.

\section{Custo de Administração dos Recursos da PMM}

A Diretoria de Administração exerce influência na avaliação, por gerar despesas relativas à gestão dos recursos utilizados nas atividades de implantação e manutenção da arborização urbana. $O$ cálculo da influência dessa diretoria no valor de manutenção da arborização (VARB ${ }_{\text {adm }}$ ) foi realizado considerando a razão custo administrativo/homem/árvore. Para tanto utilizou-se o montante pago no período de janeiro a junho de 1992, dividido pelo número total de funcionários da PMM (4.441) e multiplicado pelo número de funcionários envolvidos com arborização $(28,672)$, o que resultou no valor de 0,026 UFM/árvore ou US\$ 0,63/árvore. 
Da mesma maneira que os demais componentes, o custo final de administração das atividades de manutenção da arborização de Maringá no decorrer do tempo, foi calculado considerando taxa de juros nominal de $6 \%$ ao ano, pela seguinte fórmula:

$\mathrm{CAD}_{\mathrm{n}}=\mathrm{VARB}_{\mathrm{adm}} \times \mathrm{FC}$

Seguindo o estabelecido para os demais componentes, considera-se para o cálculo do componente custo de administração o acréscimo de uma vez o valor da $\mathrm{VARB}_{\mathrm{adm}}$ a cada 30 meses de idade da árvore.

\section{TOTALIZAÇÃO DOS CUSTOS COMO MÉTODO DE AVALIAÇÃO MONETÁRIA DE ÁRVORES URBANAS}

O método de avaliação desenvolvido, destina-se ao estabelecimento do valor individual de árvores componentes da arborização de ruas, com base nos custos de manutenção gerados pelas mesmas. A forma de avaliação de árvores utilizada pelo método consiste na aplicação de uma equação de primeiro grau, cuja variável principal é a idade de plantio. As constantes previstas na fórmula são relativas ao custo médio da muda adequada ao plantio nas ruas e à somatória das despesas correntes, das despesas com bens de capital e dos custos administrativos, gerados pelas atividades de poda de galhos e de raízes, controle fitossanitário, remoção de árvores e outros tratos culturais. É aplicado nos cálculos, também, um fator de correção em função da idade da árvore e da taxa de juros considerada na análise (6\% ao ano). Resumidamente o valor da árvore na idade "n" $\left(\mathrm{VA}_{\mathrm{n}}\right)$ é determinado pela fórmula:

$\mathrm{VA}_{\mathrm{n}}=\{$ custo da muda $\mathrm{x} F \mathrm{FC}+[($ custos correntes $\mathrm{x} F C)+($ custos com bens de capital x FC) + (custos de administração x FC)]\}

Apesar de ter sido utilizada a cidade de Maringá como unidade piloto para o desenvolvimento do método, o mesmo pode vir a ser adaptado para outras cidades. $\mathrm{O}$ custo da muda utilizado no método proposto é muito próximo para todas as espécies pesquisadas não produzindo diferenças significativas no valor final da árvore para a situação analisada em Maringá. Por este motivo o cálculo final dos valores por idade, foi realizado considerando o custo médio das mudas praticado na região.

O método é apresentado sob a forma de uma tabela de única entrada (Tabela 2), sem listagens auxiliares, onde o valor da árvore é obtido através de consulta simples correspondente a sua idade. $\mathrm{O}$ valor resultante da avaliação expressa o custo médio de implantação e manutenção de cada árvore de rua. Para facilitar o entendimento, os valores finais foram apresentados em UFM de Maringá e em dólares norte-americanos. 
Tabela 2 - Valores de árvores de ruas de Maringá, em função do custo médio da muda, para idades entre 1 e 50 anos, com valor final expresso em UFM e dólares norteamericanos

Table 2 - Street trees values in Maringá, as a function of average costs of seeds, to ages between 1 and 50 years, expressed in fiscal units of Maringá (UFM) and American dollars (US\$)

\begin{tabular}{lcc|ccc}
\hline Idade & $\begin{array}{l}\text { Valor em UFM } \\
\text { Age }\end{array}$ & $\begin{array}{c}\text { Valor em US } \text { in } U F M \\
\text { Value in US } \$\end{array}$ & $\begin{array}{c}\text { Idade } \\
\text { Age }\end{array}$ & $\begin{array}{c}\text { Valor em UFM } \\
\text { Value in } U F M\end{array}$ & $\begin{array}{c}\text { Valor em US\$ } \\
\text { Value in US\$ }\end{array}$ \\
\hline 1 & 2,495 & 59,40 & 26 & 58,321 & $1.388,61$ \\
2 & 2,710 & 64,52 & 27 & 61,981 & $1.475,78$ \\
3 & 4,915 & 117,02 & 28 & 67,840 & $1.615,27$ \\
4 & 5,279 & 125,70 & 29 & 72,088 & $1.716,41$ \\
5 & 5,669 & 134,97 & 30 & 76,598 & $1.823,79$ \\
6 & 8,114 & 193,20 & 31 & 83,418 & $1.986,17$ \\
7 & 9,678 & 206,63 & 32 & 88,625 & $2.110,17$ \\
8 & 11,249 & 267,84 & 33 & 96,129 & $2.288,82$ \\
9 & 12,006 & 285,86 & 34 & 102,119 & $2.431,46$ \\
10 & 12,810 & 305,01 & 35 & 108,482 & $2.582,96$ \\
11 & 15,696 & 373,73 & 36 & 117,270 & $2.792,19$ \\
12 & 16,727 & 398,26 & 37 & 124,566 & $2.965,92$ \\
13 & 19,795 & 471,32 & 38 & 134,283 & 3.197 .29 \\
14 & 21,079 & 501,89 & 39 & 142,630 & $3.396,03$ \\
15 & 22,441 & 534,32 & 40 & 151,490 & $3.606,97$ \\
16 & 25,922 & 617,20 & 41 & 162,929 & $3.879,35$ \\
17 & 27,585 & 656,79 & 42 & 173,041 & $4.120,10$ \\
18 & 31,321 & 754,76 & 43 & 185,750 & $4.422,70$ \\
19 & 33,316 & 793,25 & 44 & 197,269 & $4.696,97$ \\
20 & 35,434 & 843,68 & 45 & 209,499 & $4.988,18$ \\
21 & 39,715 & 945,62 & 46 & 224,519 & $5.345,79$ \\
22 & 42,229 & $1.005,46$ & 47 & 238,427 & $5.676,95$ \\
23 & 46,870 & $1.115,97$ & 48 & 255,170 & $6.075,59$ \\
24 & 49,824 & $1.186,32$ & 49 & 270,971 & $6.451,82$ \\
25 & 52,960 & $1.260,98$ & 50 & 287,748 & $6.851,29$ \\
\hline
\end{tabular}

Comparando-se os valores de árvores estabelecidos pelo método com os previstos pela Lei $2.585 / 89$, aparentemente o primeiro estabelece valores menores para todas as faixas de idade. Avaliações realizadas pela Lei provocam situações onde árvores com $131 \mathrm{~cm}$ de CAP tenham valor de 200 UFM maior do que árvores com $130 \mathrm{~cm}$ de CAP, avaliadas pelo método ora estabelecido, diferença excessiva para árvores de mesma espécie que sofreram o mesmo tipo de manutenção ao longo de suas vidas e com diâmetros muito próximos. O método ora proposto, apesar de ter sua aplicação dependente do conhecimento da idade da árvore, considera como meio de avaliação as despesas efetivamente realizadas em função da árvore e, portanto, utiliza informações com caráter mais objetivo do que outros métodos conhecidos. Ainda, o método não permite a obtenção de resultados diferentes para avaliações de uma mesma árvore, quando utilizado por mais de uma pessoa, ou seja, não sofre influências de caráter subjetivo ou pessoal do avaliador. 


\section{CONCLUSÕES}

O método de avaliação monetária desenvolvido, é aplicável a árvores individuais urbanas, sendo necessário para sua utilização informações relativas ao custo individual médio de mudas por espécie e à idade da árvore objeto da avaliação. $\mathrm{O}$ método baseia-se nos custos relativos à aquisição de mudas, bens de capital, despesas correntes de manutenção da arborização, despesas administrativas, correção monetária e taxa de juros para o período considerado.

O principal limitante apresentado pelo método é quanto à necessidade de conhecimento da idade da árvore, sendo impossível sua correta aplicação sem que se tenham referências precisas do ano de plantio do exemplar objeto da avaliação.

As fórmulas apresentadas no presente método são adequadas à avaliação de árvores individuais que sejam submetidas a manejo semelhante ao realizado em árvores de rua, ou seja, poda leve, poda pesada, poda de raízes e controle fitossanitário.

O método é adaptável a outras cidades, bastando, para isto, a coleta de alguns dados relativos a estrutura e custos do setor responsável pela arborização e algumas informações complementares relativas ao mercado privado de prestadores de serviços e fornecedores de insumos.

Os valores de árvores com idade entre 1 e 50 anos determinados pela fórmula de avaliação são equivalentes, respectivamente, a 2,5 UFM (US\$ 60) e 287 UFM (US\$ 6.850). Os valores resultantes da aplicação do método de avaliação são menores do que os previstos na Lei 2.585/89 de Maringá e refletem apenas os custos gerados pela manutenção das árvores para o intervalo de tempo.

Valores adicionais aos estabelecidos pelo método podem ser cobrados com sentido punitivo ou educativo, principalmente, em se tratando de avaliações de árvores com relevante interesse ecológico, funcional, estético, religioso, histórico e cultural, entre outros.

\section{BIBLIOGRAFIA CITADA}

AKROYD, T. 1986. Trees and the law. Arboricultural Journal, 10: 233-240.

BARTEINSTEIN, F. 1981. The future of urban forestry. Journal of Arboriculture, 7(10): 261-267.

BERNATZKY, A. 1978. Tree ecology and preservation. Elsevier Scientific Publishing Company, New York. p. 313-323.

BRYANT, R. 1983. Tree work insurance. Arboricultural Journal, 7: 321-326.

DETZEL, V. A. 1992. Arborização Urbana: importância e avaliação econômica. In: Congresso Brasileiro Sobre Arborização Urbana, 1, \& Encontro Nacional Sobre Arborização Urbana, 4. Anais. Prefeitura Municipal de Vitória, Vitória, p. 39-52. 
DeVOTO, D. F. 1979. Paper from municipal trees. In: Conference On Alternatives To Urban Waste Wood Disposal, 1979. Proceedings. Charleston, p. 52-61.

DREISTAD, S. H. \& DAHLSTEN, D. L. 1986. Replacing a problem prone street tree saves money; a case study of the tuliptree in Berkeley, California. Journal of Arboriculture, 12(6):146-149.

DWYER, J. W.; McPHERSON, E. G.; SCHROEDER, H. W. \& ROWNTREE, R. A. 1992. Assessing the benefits and costs of the urban forests. Journal of Arboriculture, 18(5): 227-234.

FARHAT, C. B. 1990. Valores da arborização - Maringá/PR. In: Encontro Nacional Sobre Arborização Urbana, 3. Anais. FUPEF, Curitiba, p.153-159.

FUNDAÇÃO INSTITUTO BRASILEIRO DE GEOGRAFIA E ESTATÍSTICA IBGE. 1982. Censo demográfico brasileiro: dados distritais IBGE, Rio de Janeiro. Vol. I, Tomo 3, $N^{\circ}$ 18, p. 415 \& Tomo 4, $\mathrm{N}^{\circ}$ 20, p. 425.

FUNDAÇÃO INSTITUTO BRASILEIRO DE GEOGRAFIA E ESTATÍSTICA IBGE. 1991. Censo demográfico brasileiro: dados distritais. IBGE, Rio de Janeiro. (Relatório parcial não publicado).

GREY, G. W. \& DENEKE, F. J. 1978. Urban Forestry. John Wiley and Sons, New York. p. 154-173.

INTERNATIONAL SOCIETY OF ARBORICULTURE - ISA. 1988. Valuation of landscape trees, schrubs, and other plants - A guide to the methods and procedures for appraising amenity plants. $7^{\text {th }}$ edition. Urbana. $49 \mathrm{p}$.

JIM, C. Y. 1987. Urban trees in Hong-Kong - benefits and constraints. Arboricultural Journal, 11: 145-164.

JOHNSTONE, R. A. 1983. Management techniques for utility tree maintenance. Journal of Arboriculture, 9(1): 17-20.

KIELBASO, J. J. 1971. Economic values of trees in the urban locale. In: Symposium on the Role of Trees in the South's Environment at Athens, 3. Procedings. p. 82-94.

KOSTICHA, C. J. \& CANNON Jr., W. N. 1984. Costs of Dutch Elm Disease management in Winsconsin communities. Journal of Arboriculture, 10(9):250-254.

LEMPICKI, E. A. 1979. Coordinating producers and consumers of urban wood residues. In: Conference On Alternatives To Urban Waste Wood Disposal, 1979. Proceedings. Charleston. p. 117-120. 
LOHMANN, G. 1988. How valuable are the street trees of Lambeth bourough? Arboricultural Journal, 12: 1-16.

LOWERY, J. W. 1979. Firewood from municipal trees. In: Conference On Alternatives To Urban Waste Wood Disposal, 1979. Proceedings. Charleston. p. 68-72.

MICHIGAN STATE UNIVERSITY FORESTRY DEPARTMENT \& MICHIGAN FORESTRY AND PARK ASSOCIATION. 1975. Chade tree evaluation chart. MFPA, Lansing - MI. 4 p.

MICHIGAN STATE UNIVERSITY FORESTRY DEPARTMENT \& MICHIGAN FORESTRY AND PARK ASSOCIATION. 1986. Michigan Tree Evaluation Guide. MFPA, Lansing - MI. 18 p.

MILANO, M. S. 1984. Avaliação e análise da arborização de ruas de Curitiba/PR Dissertação de mestrado, Curso de Pós-Graduação em Engenharia Florestal, Universidade Federal do Paraná. 130 p.

MILANO, M. S. 1988. Avaliação quali-quantitativa e manejo da arborização urbana: exemplo de Maringá - PR Tese de doutorado, Curso de Pós-Graduação em Engenharia Florestal, Universidade Federal do Paraná. 120 p.

MILLER, R. W. \& SILVESTER, W. A. 1981. An economic evaluation of tre pruning cycle. Journal of Arboriculture, 7(4): 109-112.

MILLER, R. W. 1988. Urban forestry - Planing and managing urban greenspaces Prentice Hall, New Jersey. 404 p.

MILLS, G. A. 1979. Recovery of energy from solid waste - an alternative to landfill disposal. In: Conference On Alternatives To Urban Waste Wood Disposal, 1979. Proceedings. Charleston. p.100-107.

MORALES, D. J. 1980. The contribuition of trees to residencial properti values. Journal of Arboriculture, 6(11): 305-308.

NOSSE, R. A. 1983. Crew evaluation. Journal of Arboriculture, 9(5): 141-144.

PARDO, R. 1979. Urban waste wood: the challenge and the future. In: Conference On Alternatives To Urban Waste Wood Disposal, 1979. Proceedings. Charleston. p. 121-123.

PREFEITURA MUNICIPAL DE MARINGÁ - PMM. 1988. Perfil - Plano municipal de desenvolvimento. PMM, Maringá. 245 p. 
REETHOF, G. \& HEISLER, G. M. 1976. Trees and forest fo noise abatment and visual screening. U. S. For. Serv. Gen. Tech. Rep. NE-22. p. 39-48.

SHERWOOD, S. C. \& BETTERS, D. R. 1981. Benefit-costs analysis of municipal Dutch Elm Disease control programs in Colorado. Journal of Arboriculture, 7(11): 291-298.

SMITH, W. \& DOCHINGER, L. S. 1976. Capability of metropolitan trees to reduce atmospheric contaminants. U. S. For. Serv. Gen. Tech. Rep. NE-22. p. 49-59.

TAKAHASHI, L. Y. \& MARTINS, S. S. 1987. Parque Ingá: potencial de uma área verde urbana de recreação. In: Encontro Nacional Sobre Arborização Urbana, 2. Anais. Maringá, p. 215-221.

WALKER, D. 1979. Mulch from limb and trunk debris. In: Conference On Alternatives To Urban Waste Wood Disposal, 1979. Proceedings. Charleston. p. 62-67.

WHITMER, G. L. 1979. Legal and environmental issues surrounding urban waste wood. In: Conference On Alternatives To Urban Waste Wood Disposal, 1979. Proceedings. Charleston. p. 111-116. 